\title{
Design a platform of supply and demand of technical skills talent in Tianjin Binhai New Area
}

\author{
Wangkun \\ The cooperative education office of Tianjin Vocational Institute \\ Tianjin China \\ tjzhiye@163.com
}

\begin{abstract}
Tianjin economic development need large quantities of technical skills talent as the support, and in recent years there has been " labor shortage", especially the shortage of technical skills talent demand, has become a constraining the Binhai New Area to enhance regional competitiveness, adjust the industrial structure, change the mode of economic development is one of the bottlenecks. This paper presents the design of the Binhai New Area of technical skills talent platform of supply and demand functions, tasks and operation mechanism, to explore the solution of new economy rapid development process encountered " the difficult employment, labor shortage" and other human resources supply and demand problem from strategic planning level.
\end{abstract}

Keywords- Tianjin Binhai New Area; technical skills talent; platform of supply and demand; design

\section{INTRODUCTION}

Tianjin is an economic growth of the city, in 2011 the GDP reached 11190.99 yuan, year-on-year growth of $16.4 \%$, which, in the manufacture of industrial clusters characterized the Binhai New Area of GDP reached 620690000000 yuan, up $23.8 \%$. At the same time, " labor shortage" the emergence of a serious imbalance, the formation of fast with the development of the regional economy, on the one hand is the rapid development of work the region economy, to absorb more labor employment, no longer be forced to leave one's hometown and lead to " labor shortage"; on the other hand is very much " after 90 ", " after 80 " students do not willing to labor-intensive enterprises and technical work requirements of the enterprise employment and lead to " labor shortage"; a serious shortage of technical skills talent has become Tianjin economic development, especially become the Binhai New Area to enhance competitiveness of the region, the adjustment of industrial structure, change the mode of economic development is one of the bottlenecks. Therefore, exploring the construction technical skills talent supply and demand platform is strategically addressing new district economic development encountered in the process of " difficult employment, labor shortage " problem of the human resource supply and demand of important ways and means.

\author{
II. DESIGN IDEAS AND THE BASIC FRAMEWORK \\ PLATFORM OF SUPPLY AND DEMAND OF BINHAI NEW AREA \\ AND TECHNICAL SKILLS TALENT.
}

\section{A. Design}

Starting from the immediate effect of talent demand contradiction to solve bullwhip effect and technical skills training technical skills talent of the occupation education services, to enhance the Binhai New Area of economic development as the basic goal, in the Binhai New Area government as the leading factor, the enterprise as the main body, the main occupation colleges, market-oriented operation as the main method, based on the deep " political school-enterprise cooperation" mechanism, talent supply and demand information system as the carrier, through the construction of technical skills talent supply base and improve staff training center of Binhai New Area efficiency, build technical skills talent supply and demand platform, forming three linkage, win-win talent demand, supply mechanism, effectively solve the problem of regional economic development, especially the problem of lack of technical skills talent manufacturing industry, enhance the pertinence and effectiveness of the occupation education service construction of Binhai New area.

\section{B. The basic framework}

Binhai New Area technical skills talent supply and demand platform is dominated by the government, educational institutions and enterprises to participate in the occupation of the three linked, win-win technical skills talent demand, supply system. Platform of supply and demand and technical skills talent consists of five aspects:

1) To establish a deep " political school-enterprise cooperation " technical skills talent training mechanism;

2) The government leading new technical skills talent supply and demand information system construction;

3) The establishment of " Binhai New Area technical skills talent supply base of 3 combined with higher vocational education ";

4) The establishment of " Binhai New Area and technical skills talent training center of Tianjin Vocational Institute based on the Pudong New Area Government 4 ";

5) The government promulgated the "technical skills talent points for residence ( green card ) system ". 


\section{THE FUNCTION AND TASK OF THE PLATFORM OF SUPPLY AND DEMAND OF TECHNICAL SKILLS TALENT IN TIANJIN BINHAI NEW AREA}

\section{A. " training technical skills talent of school-enterprise cooperation mechanism. "}

1) the Binhai New Area government as a " political school-enterprise cooperation " leading. The new government to take training technical skills talent as an important support of regional economic development, placed in a more important strategic position, give full play to the government in enterprises and institutions to carry out the occupation in school-enterprise cooperation plan, guide, regulate, communication, service function, introduced the " school-enterprise cooperation Binhai New Area to promote the Ordinance " and the corresponding policy, regulations and supporting the establishment of project, establish occupation education and industry cooperation dialogue mechanism, integration of College-Enterprise advantages, promote and guarantee the school-enterprise cooperation.

2) In 2 enterprises in in subject as " political schoolenterprise cooperation". Enterprises to " into the overall planning for enterprise development to cultivate technical skills talent and cooperation " policy, actively play technology, equipment, information and other resources, timely exchange of personnel demand information, the implementation of the " order form" training, receiving post occupation college students and teachers to practice internship training, practical training base construction, development, organization enterprise staff skills and training etc..

3) Occupation colleges as " political school-enterprise cooperation " main. Occupation colleges should adapt to the Binhai New Area of economic development and industrial upgrade requirements, embody the concept of lifelong education, close strategic cooperation with enterprises, in the development of " order" training program, to carry out extensive cooperation employment guidance and employment recommendation, teacher exchanges and training, staff training and continuing education, research and technology transformation etc.. Occupation colleges should take the initiative in order to improve the technology level, talent and technology skilled occupation quality and improve the competitiveness of the enterprise market services, to become the enterprise staff knowledge update and continuing education of the gas station.

\section{B. The Binhai New Area of technical skills talent supply and demand information system}

1) The establishment of Binhai New Area human resources management mechanism

Binhai New District People Club Bureau of establishing human resource management mechanism, according to the industry development strategy of human resources development strategy, analysis of present situation of human resource development, enterprise diagnosis, for enterprise decision-makers accurately, timely provision of a variety of valuable information, the formation of the enterprise's strategic target, and to achieve the goal of making a specific plan of action; establish improve the mechanism of the human resource management system, system, establishment, human resource management, the formulation and implementation of the human resources management process, solve the human resources management problems on the operational level; to create suitable for technical skills talent to work with development, harmonious environment for human resources management.

2) Create the Binhai New Area of technical skills talent supply and demand information website

Led by the government, the Binhai New Area of Tianjin Vocational Institute undertakes the Binhai New Area, create technical skills talent supply and demand website. Site headquarters and central located in Binhai New Area People Club Bureau, people club Bureau of human resources management agencies responsible for the entire site planning, coordination, management and service, and new technical skills talent supply and demand, training, employment, political school-enterprise cooperation, competition, technology innovation, science and technology incubator project, Achievements Exhibition service resources responsible for production site; technology application, network operation and maintenance, enterprise employing information collection and induction, publishing talents training ways and means of information occupation university; enterprises to provide timely information for people, industry regularly publish information technology skills talents demand forecasting.

3) Supply and demand 3 organizational skills of Binhai New Area talent fair

District People Club Bureau Collection enterprise information demand and occupation college talent cultivation, and regularly organize technical skills talent fair, through the rational allocation model adjustment and technical skills talent market operation; establish occupation colleges and enterprises channels of dialogue, regularly organize enterprises into the campus, the school into the enterprise, and related workers will, the organization of industry and school for special professional ( cases of accounting, secretarial single enterprise needs less overall demand, many professional ) " order training ".

\section{The establishment of "Binhai New Area technical skills talent supply base combined with higher vocational education colleges "}

1) Create a "technical skills talent supply base 1 Binhai New Area government "

Binhai New Area government to do technical skills talent reserve, to meet the needs of enterprises, the need to establish a number of technical skills talent supply base, enhance the training and the overall quality of the " transfer station " for college graduates occupation the Midwest and the local young labor resources to establish a new enterprise employment occupation skill, forming new technology talents "reservoir ". The new government will give full play to the advantages of industry, policy, environment, introduce the corresponding policies, coordinate with relevant departments to subsidies, grants, and other forms of training 
to mobilize technical skills talent, enthusiasm and to the new transport.

2) Tianjin Vocational Institute " Binhai New Area construction technical skills talent supply base "

As the national occupation education demonstration zone of the leading school, Tianjin Vocational Institute has a strong leading role and exemplary role in the country. The school with the joint running of this influence and the central and western regions of the occupation college, the construction of Binhai New Area of " technical skills talent supply base ". Talent supply technical skills three:

One, " to a new higher vocational employment transfer in the midwest ". Tianjin Vocational Institute receiving part to Binhai New Area to the Midwest college students employment " order class" or " title class ", from six months to a year's time, professional skills, training and training in Tianjin Vocational Institute, and then directly facing the new employment. The formation of the central and Western Colleges and technical skills talent supply alliance.

Two, " the first recruitment, training, and after delivery in the Midwest young labor ". Tianjin Vocational Institute and Tianjin Municipal Economic Cooperation Office jointly, for young labor resources in the central and western regions to the Binhai New Area of enterprises to hire, pass the exam admission conditions to implement the " order training ", do not conform to the gang to the position requirements of enterprises training before admission conditions, and then transported to the new employment. The formation of supply alliance labor transfer in the central and Western regions.

Three, " started reserve and technical skills talent for new projects ". The Bridge District People Club Bureau set up with Government Investment Promotion Bureau and other relevant departments, the introduction of time settled in the New District in the project, occupation university becomes the enterprise technical skills talent of the supply side, recruitment and enrollment double combination, establish " cooperation title class " schools and enterprises to develop training plan, teaching content reform, culture into the enterprise culture and occupation accomplishment, enhance their sense of identity, student employment and enterprise operating over the same period, greatly shorten the project of human resource cost.

D. Tthe establishment of "Binhai New Area and technical skills talent training center of Tianjin Vocational Institute based on the new government "

1) Social training is an important function of government, should be in the strategy to plan and co-ordinate. As taking social training as the main channel of technical skills talent reserve stock increase, is the two time the investment of talent reserves, has strong pertinence, Binhai New Area government to include regional economic development strategy planning, and strive to explore ways to gather technical skills talent for regional economic development. The government can give the enterprise staff training subsidy, subsidy scheme, policy and legal support, can effectively guarantee the implementation of training, improve staff skill level and occupation accomplishment, meet the reasonable allocation of regional economic development on the skills and high skill talents, enhance the core competitiveness of economic zone.

2) Important functions of social training and higher vocational education serving the regional economy. Social training of vocational institutions, is the objective requirement of regional economic and social development, is also a school of their own survival and development needs. Tianjin Vocational Institute, using their own teachers, teaching, equipment and space advantage depends on the government for the establishment of " Binhai New Area of Tianjin Binhai New Area and technical skills talent training center " nearly 400000 blue-collar army, relying on the new government to give policy and financial support, combine the training content and business strategy, skill training and quality improvement closely, social training closely combined with the skills to identify, short-term training and education to improve closely, effectively improve the conversion rate of training, the training work of Binhai New Area, solid technical skills talent bigger, stronger.

3) Employee training is the bounden duty. For staff to provide high quality, comprehensive, diversified training opportunities, with effective training to become human capital, human capital to the core competitiveness of enterprises to forge, to make enterprises bigger and stronger. Enterprises make full use of the 3\% training fund, organize employees to enhance training center in skill and quality, enterprises can reduce the cost of human resources, can also enjoy the new government to give some subsidies for training and support. Conduct employee skill tournament form through training and staff, lead the staff team building, improve human resources area, promote high technology talents proportion, to enhance the core competitiveness of enterprises.

\section{E. The government promulgated the " technical skills talent points for residence ( green card) system "}

The government promulgated the " technical skills talent points for residence ( green card ) system for vocational college students, " provincial graduates and contribute to the construction of Binhai New Area provincial technical ability with the conditions stipulated in the system could be carried out the points for a green card, and green card holders enjoy equal treatment in the Binhai new area of Tianjin city citizen inner, buy a house insurance, children's education, and 5 years working in the Binhai New Area, can be converted to Tianjin public official. ( as shown in the technical skills of Binhai New Area talent points for residence ( green card ) system design )

Five aspects through the design of the system together, (for example: improvement of salary system; technical skills talent incentive mechanism; high skill talent introduction mechanism; big project reserves and technical skills talent system. ) Implementation by the government for the technical skills of Binhai New Area Talent supply and demand of social service dominant, occupation colleges and enterprises to participate in the. 


\section{GUARANTEE MEASURES TO BUILD A PLATFORM OF SUPPLY AND DEMAND OF BINHAI NEW AREA AND TECHNICAL SKILLS TALENT.}

In view of building the Binhai New Area of technical skills talent supply and demand platform about three dimensions of political cooperation, we must strengthen the Binhai New Area government to build platform leadership and overall planning, practice relates to the content in the work should be subordinated to and serving the Binhai New Area of the overall economic and social development, therefore, the implementation of a platform of supply and demand of Binhai New Area technical skills talent to put in the Binhai New District economic development level to promote and innovation.

1) Good top-level design, enhance the overall situation awareness. Establishment led by the Binhai New District People Club Bureau leadership, consisting of the Pudong New Area government relevant functional departments, colleges and enterprises under the leadership of the " construction " of Binhai New Area and technical skills talent supply and demand platform project steering committee, responsible for planning, coordination of project implementation, difficulties and problems encountered in guide to resolve project implementation process.

2) To build the platform of supply and demand of Binhai New Area and technical skills talent, encourage "pilot ". On four aspects of work to establish the platform of leading group project, specifically responsible for the project organization, management, coordination and summary, propaganda work. Assume for each unit of the mission, detailed objectives, measures, promote stratification, step-bystep implementation, key breakthrough, bold innovation. Develop key projects and key links bold experiment, encourage " pilot", the first breakthrough, make higher vocational education plays an important role in the Binhai New Area of training technical skills talent and supply in the advantage of industry, become the scientific development, harmonious development, harmonious development model.

3) By the Tianjin Vocational Institute led the establishment of " Binhai New Area technical skills talent research center ", research report compilation of annual, special research fund set up by the government of Binhai New Area, budget, final accounts and audit the use, in accordance with the project management mode, to ensure the efficiency in the use of funds.

4) The implementation of standardized management, improve work efficiency. Coordination mechanism innovation, and further strengthen the management behavior, promote the implementation of the various elements of the system between the government, the school and enterprise cooperation, coordination, promote the " political schoolenterprise cooperation " coordinated, orderly development; innovation quality monitoring mechanism, ensure the effectiveness of the work of the specification.

\section{ACKNOWLEDGMENT}

This is Tianjin Education Science " Twelfth Five-Year Plan" key issue " stage achievements and research and practice of higher vocational education attribute " innovative talent training mode based on Work-study combination. ( No.: VE2005 )

\section{REFERENCES}

[1] Ye Rongde city high skill talent supply and demand imbalance of [C].36-42.

[2] Wang Yiqun, New exploration of the economic development of higher vocational education service area [J].Journal of Enshi Technical College ( Comprehensive Edition ), 2010 ( 3 ) :1-4

[3] Wang Hong. Higher vocational education level to boost the Harbin economy Development mode transformation [J]. Journal of Harbin Vocational and Technical College, 2011 ( 2 ): 1-3.

[4] Liu Li. Construction of platform of social services to enhance the social service ability of [J]. Hal In Journal of Career Technical College, 2011 ( 2 ): 10-12.

[5] Lu Shihua, Feng Kejiang. The supply of high skill talent of [J]. of Baotou Vocational \& Technical College Report, 2009 ( 2 )

[6] Tengfei. Difficulties and strategy [ J] skills shortages. Adult education, 2011(8).

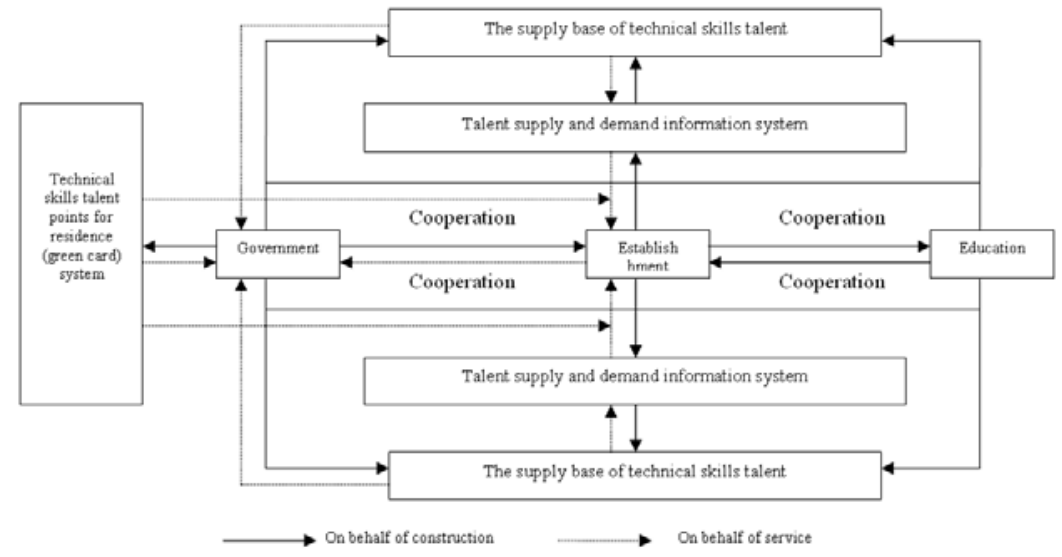

Figure 1. The basic framework of platform of supply and demand of technical skills talent in Tianjin Binhai New Area 